\title{
Talking Over Glass: Learning Transmission Rates Through the Telephone Game
}

Like many parents, I first became involved at the local elementary school because I had children in the system. My initial invitation came as the classic "Show and Tell" request from the grade school teacher via my son. "Oh, your father works with lasers. That sounds interesting. Can you ask him if he will tell us about his job?" Since I was active in the community, coaching YMCA youth sports teams and with the Cub Scouts, I was already acquainted with many of the children. This made the students, the teacher, and myself much more comfortble. Comfort is a key element in making a school visit a success.

After several less-than-spectacular talks, it became obvious that even with a "touchy-feely" time at the end of the talk, only a handful of children managed to stay tuned in for the entire period. So I introduced class participation into the talks. Here, too, I learned lessons the hard way. Only one student can effectively view a hologram at a time and the waiting line moves slowly relative to a child's attention span. The balance of the class eventually degrades into chaos. Finally, relying on my experience with coaching youth team sports, I started dividing the classes into teams and experimenting with games that reinforced the topics I was addressing.

At first, there was no documented formalism to these games. In the 1990-91 academic year I was invited by the Bell
Atlantic-AAAS Institute to team up with Tony Alestick, an eighth-grade science teacher in the Timberlane Junior High School, Hopewell Valley, New Jersey. In this partnership I developed the games into a natural extension of the classroom instructional units. The games are used to illustrate concepts that are part of a classroom talk that goes by various titles, all variations on the theme "Talking Over Glass." Tony and I were selected as one of the partnerships invited to the February 1991 AAAS Meeting in Washington, DC. As a result of having to make that presentation, I had to document in viewgraph form some of the games that I had always simply orchestrated from memory.
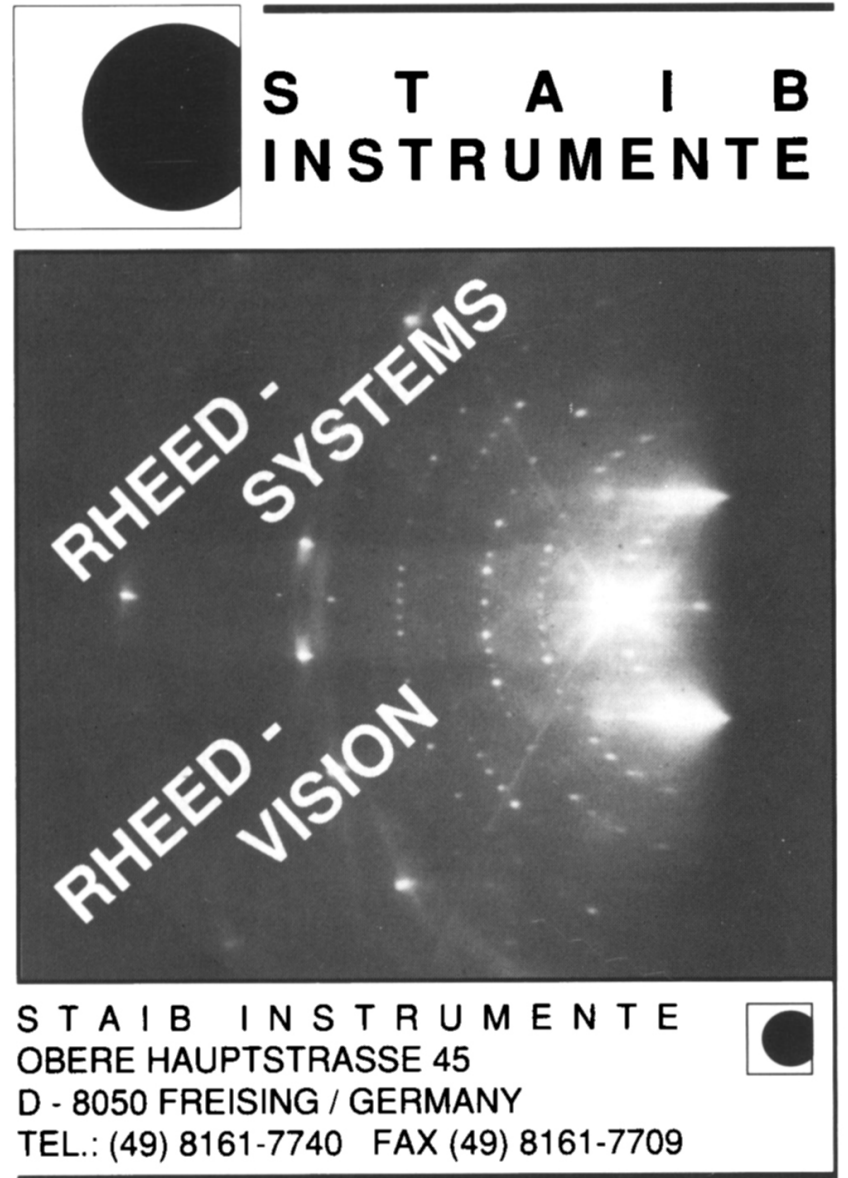

Circle No. 52 on Reader Service Card.

Please visit Booth No. 903 at the MRS Equipment Exhibit/Table Top Display in Boston, December 1-3, 1992.

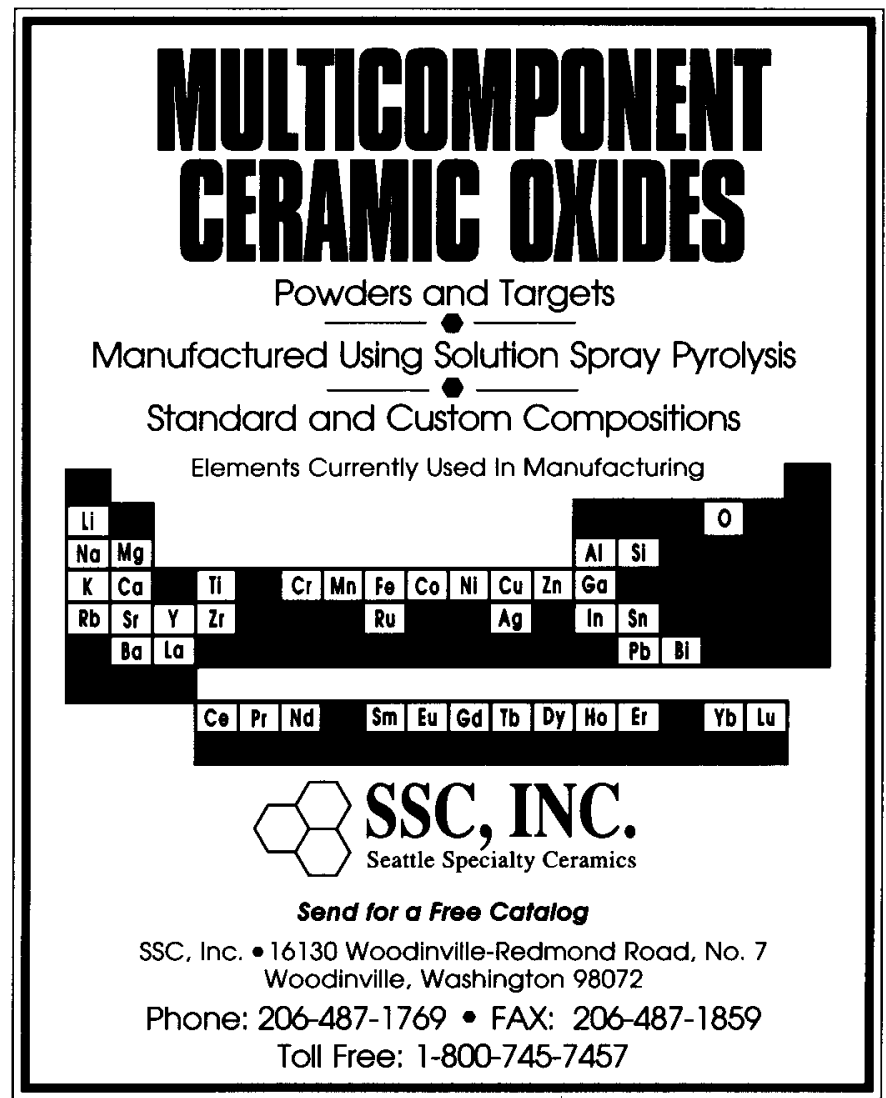

Circle No. 53 on Reader Service Card.

Please visit Booth No. 107 at the MRS

Equipment Exhibit/Table Top Display in

Boston, December 1-3, 1992. 
The two classroom games described below were developed over several years of trial-and-error iterations with grade school and middle school classes. I use the word games(s) to emphasize my personal bias for fun-demonstration or participative experiment are good synonyms. Both of these age groups invariably have a unit on light, so optical communications is a natural extension of the curriculum into the technology of today's global information network.

\section{The Telephone Game}

The telephone game is used to emphasize the elements of a transmission network. The objective of the game is to send a ten-word message through a chain of students with as little message distortion (as few errors) as possible. A typical class size is 24 students. I would make three teams of eight students each: AT\&T, MCI, and
Sprint, of course. It is important to gain team esprit de corps by appealing to students' competitive and sweet-tooth instincts. Only the winning team gets the candy-immediate positive feedback. Peer pressure is used to help insure against the one student who would intentionally transmit all errors just for the spite of it. I'll go with, "Your ear is full of gray lint and brown wax," over "Alexander Graham Bell invented the telephone to help the deaf" every time. Take the three messagestarting students into the hall so they can really memorize the message. Then have the message whispered student-tostudent down the chain. The last student writes down the message, so there isn't any argument or changing of the message when the other teams' results are announced.

Then it's time to tally the scores. Transmission systems are qualified using two relatively simple performance metrics: Bit Error Rate (BER) and Bit Rate Distance Product (BRDP). For purposes of the telephone game, score the teams using BER as "number of words wrong" divided by "number of words sent" (10). Reward the winning company in real time. Walk the class through the BRDP for the number of words, approximate times, and distances they just sent their message over. In the table, I've attempted to recap this quantitative aspect of the game and compare it to typical real-world performance requirements.

\section{Hints and variations on the telephone game}

Make sure there is plenty of room between the students next in line down the chain and those whispering/listening. This avoids eavesdropping. Use different messages of equal difficulty as answers and

\section{Multilayer Materials Analysis} Yariable Angle Spectroscopic Ellipsometry (V.A.S.E)

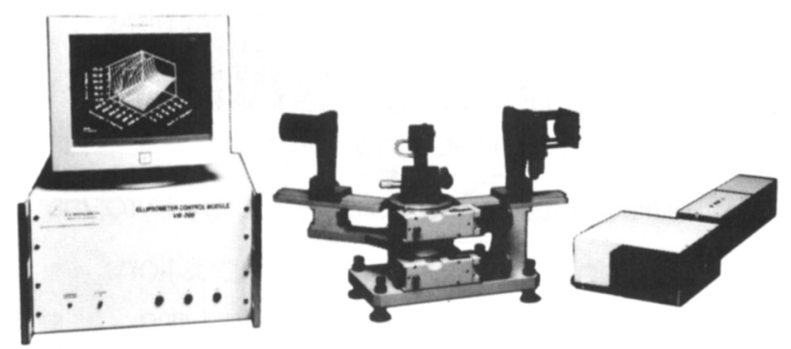

Determine:

- layer thicknesses

- optical constants

- void fractions

- surface and interfacial roughness

- wavelength range: $280 \mathrm{~nm}-1700 \mathrm{~nm}$

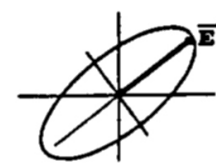

J. A. Woollam Co. - Research \& Instrumentation -

$650 \mathrm{~J}$ Street, Suite 39 Lincoln, NE 68508 USA

PH: (402) 477-7501

FAX: (402) 477.8214
Circle No. 54 on Reader Service Card. Please visit Booth No. 410 at the MRS Equipment Exhibit/Table Top Display in Boston, December 1-3, 1992.

\section{Glasses and}

\section{Amorphous Materials}

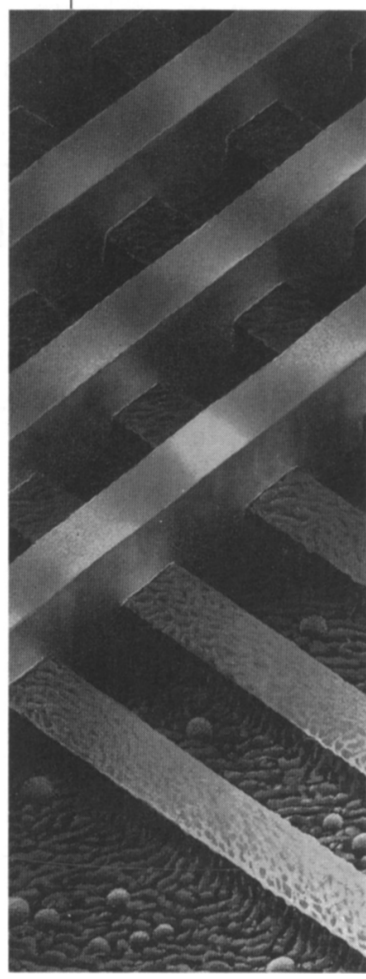

Volume 9 from the series

Materials Science and Technology

1991. XIII, 796 pages with 476 figures and 47 tables. Hardcover. $\$ 325.00$. ISBN 0-89573-697-7

This volume deals with the properties and processing of glasses and amorphous materials. It covers conventional and sophisticated glasses and glass-like materials from both theoretical and applied standpoints. Topics include • formation and relaxation $\bullet$ models for the structure of amorphous solids $\bullet$ oxide glasses $\bullet$ chalcogenide glasses $\bullet$ halide glasses $\bullet$ metallic glasses $\bullet$ glass-like carbons $\bullet$ organic glasses and polymers.

To order please contact your bookseller or:

VCH. 220 East 23rd Street, New York. NY 10010-4616, USA (Ioll free: 1-806)-367-8249) (Ioll free: |-806)-367.8249) D. 6940 Weinheim VCH. Hardstrasse 10. P.O. Box. CH-4020 Basel

VCH. 8 Wellington Court. Cambridge CBI |HZ, UK

Circle No. 55 on Reader Service Card. Please visit Booth No. 110 at the MRS Equipment Exhibit/Table Top Display in Boston, December 1-3, 1992. 
send these back in reverse order-average performance BER to determine the winning company. Play a stereo in the background to demonstrate the concept of noise-how does that impact BER? What is the impact on BER of allowing the repeaters to whisper the message back for confirmation/correction versus the listenonly mode. An all-optical analog to the game can be done using the color palettes one can find at just about every paint store. If you want to read up on the real world of telecommunications technology as a primer for the game, the following are recommended. For the basics: Understanding Fiber Optics, by J. Hecht (Howard W. Sams \& Co., Indianapolis, 1987) ISBN 0-67227066-8. For the impact of photonics: ATET Technical Journal, Vol. 66, Issue 1, "Lightwave Technology," January/ February, 1987.

\section{Time to Transmit the \\ Encyclopaedia Britannica (TTEB)}

So you finish the telephone game and calculate the BRDP for the class, then compare that to the real world number $1 \times 10^{14}$ $\mathrm{bit} \cdot \mathrm{m} / \mathrm{sec}$. If you expect that the kids will be impressed by the fourteen zeros and go "wow," you're mistaken. Junior high schoolers and grade school children have no concept of what a number that big means. To help them understand the concept, we have a game we call TTEB, or "Time to Transmit the Encyclopaedia Britannica." The idea for the game came from a New York Times article describing the information-carrying capacity of the first transatlantic undersea optical fiber cable system.

To use this game most effectively, you need to bring from the school library into the classroom the entire volume set of the Encyclopaedia Britannica on a rolling book cart. From among the students in the class, select the fastest reader. Instruct the three teams you have formed that they are to attempt to count in their heads the number of words that this student will be able to read in 30 seconds. When the teams are ready, ask the reading student to pick any volume from the entire set of the Encyclopaedia Britannica, perhaps one designating his or her favorite letter of the alphabet. Ask the student to pick a page totally at random and, within that page, to pick a topic that sounds interesting. Have the teacher time the reader for the 30-second interval (I normally look over the reader's shoulder to insure that I know where the word count started and finished). After the student is finished, the teams should huddle to put together their individual counts
Environment

Game-Descriptive

Game-Quantitative

Telephone-Quantitative

\section{Bit Error Rate}

2 wrong in 10 sent

0.2

0.000000001 or $1 \times 10^{9}$

\section{Bit Rate Distance Product}

10 words over 10 meters in about 100 seconds

$1 \mathrm{bit} \cdot \mathrm{m} / \mathrm{s}$

$1 \mathrm{Gbit} / \mathrm{s}$ over $100 \mathrm{~km}$ or $1 \times 10^{14} \mathrm{bit} \cdot \mathrm{m} / \mathrm{s}$ and come up with a best team estimate. The team with the closest estimate will be declared the winner. The game works more effectively and is more fun if, after all the teams announce their estimates, the students return to team huddles and modify their first estimate based on the word counts offered by the other teams. The "fastest reading" student usually will be able to read between 90 and 100 words in 30 seconds for a rate of 180 to 200 words per minute. After you've gone through the two cycles with each of the teams, they now have a feeling for what a bit rate of 200 words per minute means, and they can physically see the fraction of the one column from the one page from the one volume of the Encyclopaedia Britannica that is physically associated with those "200some words in one minute." You can now make the point that the entire contentthat is, every word on every line from every column from every page from every volume that the students can physically see in front of them-can be sent from that school location to a school in Europe in a fraction of a second. Of course this relates to what we in the business call increased bandwidth. It will be up to the students' generation to decide whether or not that information-carrying capacity is used for nothing more than high-definition television or is somehow used to provide immediate access to, for example, every book that's ever been written in any language throughout the entire world.

\section{Hints and Variations on the TTEB Game}

Allow the student who did the reading to rejoin his or her team to participate in the counting estimate. This student will not be able to remember a more accurate number than will those who were listening. Also, don't forget to give the reader a candy reward for being willing to stand up in front of the entire class. It can be statistically proven that the person who goes last on the "Price is Right" game show has a distinct advantage over those who have to go first or second. For this reason, in the second round of word-count estimating, the teams should be required to write down their answers, and the answers should be revealed and written on the chalkboard at the same time. By my estimate, there are seven words per line, 80 lines per page, three columns per page, 1,000 pages per volume, and 30 volumes in the edition that I used for estimation purposes. This gives $5 \times 10^{7}$ words in the 30 volumes of the Encyclopaedia Britannica. Even after a generous factor for converting words to bits, this represents only a small fraction of the bandwidth capability of the optical-fiber long-distance systems installed today.

The space provided for this Education Exchange does not allow me to go into details about how these two games draw and build on the curriculum. My intent has been to provide sufficient detail about how they are actually "played," so that interested readers may actually use them, should they venture into the classroom and want to start off with a game or two that can be used to emphasize the importance of careful listening. Good luck!

CLIF DRAPER

Clif Draper is a distinguished member of the technical staff at ATET Bell Labs Engineering Research Center in Princeton, New Jersey. He has been active as a speaker in local area schools and at civic meetings for more than fifteen years. He was the MRS Treasurer in 1985 and 1986.

The Education Exchange highlights the experiences of scientists and engineers with local schools, along with helpful hints and resources. If you would like to share your own involvement in science education, contact Finley Shapiro, Department of Electrical and Computer Engineering, Drexel University, Philadelphia, PA 19104, U.S.A.; telephone (215) 895-6749; Fax (215) 895-1695; Email: shapiro@ece.drexel.edu

To receive additional information on how you can get involved in enhancing K-12 science education, circle number 120 on the Reader Service Card. 